\title{
Coherent Resonant Millennial-Scale Climate Oscillations Triggered by Massive Meltwater Pulses
}

\author{
AXEL TIMMERMANN \\ Institut für Meereskunde, Universität Kiel, Kiel, Germany \\ HEZI GILDOR \\ Lamont-Doherty Earth Observatory, Columbia University, Palisades, New York \\ Michael SCHUlZ \\ Fachbereich Geowissenschaften, Universität Bremen, Bremen, Germany \\ ELI TZIPERMAN \\ Environmental Sciences, Weizmann Institute of Science, Rehovot, Israel
}

(Manuscript received 30 April 2002, in final form 20 January 2003)

\section{ABSTRACT}

\begin{abstract}
The role of mean and stochastic freshwater forcing on the generation of millennial-scale climate variability in the North Atlantic is studied using a low-order coupled atmosphere-ocean-sea ice model. It is shown that millennial-scale oscillations can be excited stochastically, when the North Atlantic Ocean is fresh enough. This finding is used in order to interpret the aftermath of massive iceberg surges (Heinrich events) in the glacial North Atlantic, which are characterized by an excitation of Dansgaard-Oeschger events. Based on model results, it is hypothesized that Heinrich events trigger Dansgaard-Oeschger cycles and that furthermore the occurrence of Heinrich events is dependent on the accumulated climatic effect of a series of Dansgaard-Oeschger events. This scenario leads to a coupled ocean-ice sheet oscillation that shares many similarities with the Bond cycle. Further sensitivity experiments reveal that the timescale of the oscillations can be decomposed into stochastic, linear, and nonlinear deterministic components. A schematic bifurcation diagram is used to compare theoretical results with paleoclimatic data.
\end{abstract}

\section{Introduction}

The study of climate transitions that can happen over several years to decades ("abrupt climate changes") has received much attention over the last few years, since anthropogenic greenhouse warming might have the potential to cause rapid changes in the state of the North Atlantic thermohaline circulation (THC). It was suggested that the present-day THC may be near a stability threshold that could be crossed should the THC weaken by some 25\% (Tziperman et al. 1994; Tziperman 1997). Still unsolved is the question as to whether the THC weakens considerably in response to an anticipated increase in (sub) polar temperatures and freshwater fluxes (Manabe and Stouffer 1995; Rahmstorf 1997; Rahms-

Corresponding author address: Dr. Axel Timmermann, Institute fur Meereskunde, Universität Kiel, Düsternbrooker Weg 20, Kiel D24105, Germany.

E-mail: atimmermann@ifm.uni-kiel.de torf and Ganopolski 1999; Schmittner and Stocker 1999; Stocker et al. 2001) or whether it remains relatively stable (J. M. Oberhuber 1999, personal communication; Latif et al. 2000).

A possible method to test climate models in this respect is to study whether they are able to simulate abrupt climate transitions between cold stadials and warm interstadials, the so-called Dansgaard-Oeschger (DO) events of the last glacial period (Dansgaard et al. 1984; Hammer et al. 1997). The DO events were rapid (within a few decades; see e.g., Severinghaus and Brook 1999; Lang et al. 1999) Northern Hemispheric warmings of several degrees that typically led into interstadials lasting for about 500-3000 yr.

Many studies have hypothesized on the physical mechanism leading to abrupt glacial millennial-scale climate transitions:

- Internal ice sheet instabilities-In two papers (MacAyeal 1993a,b) the possibility has been dis- 
cussed that due to internal instabilities of the Laurentide ice sheet, nonlinear ice surging oscillations with millennial timescales can be generated. According to this binge-purge oscillator model, there is a slow timescale, associated with the buildup of ice and a warming of the ice-basal interface due to geothermal heat fluxes. This leads to melting of ice at the interface and subsequent rapid discharge of ice(bergs) into the North Atlantic, also known as Heinrich events (Heinrich 1988; Bond et al. 1992, 1993).

- External forcing-Ganopolski and Rahmstorf (2001) have suggested that periodic changes of the high-latitude freshwater fluxes can trigger periodical switches of the THC that bear similarities to the observed Dansgaard-Oeschger events. Accordingly DO events can be regarded as the nonlinear response of the THC to the external forcing. The origin of the 1500-yr timescale is left open but it is speculated that it might be due to periodical changes of the solar energy output as suggested by van den Geel et al. (1999) and Bond et al. (2001). Noise can help to amplify small periodic changes in the external signal, as has been recently proposed by Alley et al. (2001). This stochastic signal amplification is known as stochastic resonance (SR) and appears to be consistent with a statistical analysis of the Greenland Ice Core Project (GRIP) climate record from Greenland (Alley et al. 2001).

- Internal ocean dynamics-It has been found in numerous model experiments (Weaver and Sarachik 1991; Sakai and Peltier 1995, 1996, 1997, 1999, 2001; Peltier and Sakai 2001; Bjornsson and Mysak 2001; Winton and Sarachik 1993; Haarsma et al. 2001; Weaver and Hughes 1994; Aeberhardt et al. 2000; Pierce et al. 1996; Winton 1997; Paul and Schulz 2002) that centennial to millennial-scale climate variability can be generated by internal oceanic processes. The key element is that a stably stratified polar water column becomes destabilized by advection/diffusion of warm subsurface waters. Once convection resumes, the THC increases rapidly, which leads to a so-called thermohaline flush. Different processes can act to stabilize the polar water column such as increased poleward heat transport, integrated freshwater fluxes or the melting of sea ice. Once the THC reduces significantly or collapses the advective/diffusive stage repeats itself.

- Long tides - The idea has been proposed (Keeling and Whorf 2000) that the interplay between earth and moon generates a long tide with a period of about 1800 yr. It has been argued that this tide might have an influence on oceanic mixing properties and might cause DO events. The astronomical period of $1800 \mathrm{yr}$, is, however, incompatible with the observed fundamental pacing period of DO events of $\sim 1470 \mathrm{yr}$ (Schulz 2002).

- Noise excitation-It has been realized (Mikolajewicz and Maier-Reimer 1994; Weaver and Hughes 1994; Aeberhardt et al. 2000; Ganopolski and Rahmstorf
2002) that the inclusion of freshwater-flux noise can excite centennial to millennial-scale oscillations in ocean and simple climate models. A question that has not been studied systematically using these models is whether noise simply excites an internal, stable climate oscillation, with a timescale that is governed by deterministic climate processes, or whether noise plays a fundamental role in shaping the dynamics underlying the oscillation. In experiments performed with the Wright and Stocker (1991) 2-D climate model, Aeberhardt et al. (2000) found that changes of stochastic freshwater forcing can excite different oscillatory regimes of the global ocean conveyor circulation. The signal-to-noise ratio (dependence of the height of the resulting spectral peak on the forcing variance) in these experiments is highly nonlinear indicating that noise plays a nontrivial role in shaping long-term oscillations, as opposed to inferences drawn from a linear stochastic excitation scenario. These conclusions are somewhat supported by a recent paper of Ganopolski and Rahmstorf (2002). The difference from the classical SR idea is that instead of amplifying an external signal noise, it excites and reorganizes internal modes of variability.

In spite of much progress, it is probably fair to state that we still lack a satisfactory detailed physical mechanism for millennial-scale abrupt climate transitions. Here we study the role of noise and oceanic processes in generating this type of climate variability using a loworder coupled climate model. Our main finding is that for realistic freshwater noise levels, meltwater pulses can trigger millennial-scale climate transitions that bear many similarities with Dansgaard-Oeschger climate variations. The meltwater pulses are interpreted as Heinrich events. The typical timescale of the simulated DO oscillations can be decomposed into deterministic (diffusive), stochastic (waiting time), and nonlinear components (due to homoclinic dynamics).

The paper is organized as follows: After a model description (section 2) we discuss the results from a transient freshwater forcing experiment designed to probe the bifurcation structure of the model and its sensitivity to meltwater pulses (section 3 ). These experiments are conducted by taking into account stochastic freshwater perturbations of different amplitudes. In section 4 we deal with noise-induced transitions, a concept that was introduced recently to explain the stability of the stochastically forced THC (Timmermann and Lohmann 2000). New concepts from dynamical systems theory that provide a framework to understand the nature of stochastically excited millennial-scale climate transitions are presented in section 5. Section 6 deals with the nonautonomous stochastic resonance idea that was previously suggested (Alley et al. 2001; Ganopolski and Rahmstorf 2002) to explain DO cycles. In section 7 we study the response of the stochastically excited coupled climate system to long-term periodic (Heinrich-event- 
like) freshwater forcing. Furthermore, sensitivity experiments are presented that focus on the synchronization between Heinrich events and the simulated Dansgaard-Oeschger events by using a conceptual ice sheet model, similar to the one used by Schulz et al. (2002). The role of ocean diffusive processes in shaping the Bond cycle is discussed in section 8. Our paper concludes with a discussion (section 9) and a summary (section 10).

\section{Model description}

Our simulations are based on a simplified coupled atmosphere-ocean-sea ice model, consisting of a zonally averaged energy balance model for the atmosphere, an oceanic box model with $2 \times 4$ boxes, representing the global ocean and a thermodynamic sea ice model (Gildor and Tziperman 2001). The ocean model (section 2a) includes four surface boxes and four deep boxes. The two polar boxes represent the regions between $45^{\circ}$ latitude and the poles, while the two midlatitude boxes include the regions between the equator and $45^{\circ}$ latitude. The polar boxes may be covered with sea ice to a variable extent (section 2a). Despite the fact that the model represents a zonally averaged global domain, the meridional transports within the Northern Ocean are mostly governed by North Atlantic contributions. Hence, in the following sections the term North Atlantic transport will be used frequently, although our model does not distinguish strictly speaking between North Atlantic and North Pacific. The atmospheric model (section 2b) is divided into four boxes, representing the same latitude bands as the ocean boxes. Each atmospheric box may have four types of lower surfaces: ocean, land, land ice, and sea ice, each with its specified albedo. The dynamic ice sheet model used in Gildor and Tziperman (2001) is not used in our study, therefore the area covered by land ice is fixed to a value that represents the conditions during the Last Glacial Maximum. All model parameters are given in Table 1. The prognostic equations are solved by a leapfrog scheme in time, using a uniform time step for all variables. A Robert time filter with $\gamma=0.25$ has been used in order to suppress the leapfrog $2 \Delta t$ mode (Haltiner and Williams 1980).

\section{a. Ocean and sea ice models}

The ocean model is a fairly standard meridional box model (Stommel 1961) similar to those used in many previous studies. The north-south lengths of the oceanic boxes $\left(L_{1}, \ldots, L_{4}\right)$ are the same as those of the atmospheric boxes above them. The width of the $i$ th ocean box is $\left(1-f_{L i}\right) W_{i}$, where $f_{L i}$ and $W_{i}$ are the land fraction and width of the $i$ th atmospheric box. The thickness of the upper ocean boxes is $D_{\text {upper }}$ while that of the lower ones is $D_{\text {lower }}$. The model dynamics include a simple frictional horizontal momentum balance, and are hydrostatic and mass conserving. Advection and diffusion
TABLE 1. Parameters used in model.

\begin{tabular}{|c|c|}
\hline Parameter, units & Value \\
\hline \multicolumn{2}{|c|}{ Ocean model } \\
\hline$L_{1}, \ldots, L_{4}\left(10^{6} \mathrm{~m}\right)$ & $4.15,10,10,4.15$ \\
\hline$r, \mathrm{~s}^{-1}$ & $2.6 \times 10^{-4}$ \\
\hline$\rho_{0}, \mathrm{~kg} \mathrm{~m}^{-3}$ & 1028 \\
\hline$K_{h}, \mathrm{~m} \mathrm{~s}^{-1}$ & $3.5 \times 10^{-4}(\mathrm{sfc}), 1.5 \times 10^{-4}($ deep $)$ \\
\hline$K_{v}, \mathrm{~m} \mathrm{~s}^{-1}$ & $4.2 \times 10^{-8}$ \\
\hline$D_{\text {upper }}, \mathrm{m}$ & 400 \\
\hline$D_{\text {lower }}, \mathrm{m}$ & 4000 \\
\hline$\tau, \mathrm{s}$ & $8.7 \times 10^{7}$ \\
\hline$C_{\mathrm{pw}}, \mathrm{J} \mathrm{kg}^{-1} \mathrm{~K}^{-1}$ & 4180 \\
\hline \multicolumn{2}{|c|}{ Sea ice model } \\
\hline$D_{\text {sea-ice }}, \mathrm{m}$ & 2 \\
\hline$\gamma, \mathrm{m}$ & 0.05 \\
\hline$\rho_{\text {sea-ice }}, \mathrm{kg} \mathrm{m}^{-3}$ & 917 \\
\hline$\tau_{\text {sea-ice }}, \mathrm{s}$ & $2.6 \times 10^{6}$ \\
\hline$L_{f}, \mathrm{~J} \mathrm{~kg}^{-1}$ & $3.34 \times 10^{5}$ \\
\hline \multicolumn{2}{|c|}{ Atmospheric model } \\
\hline$W_{1}, \ldots, W_{4}\left(10^{7} \mathrm{~m}\right)$ & $1.8,1.8,1.8,1.8$ \\
\hline$f_{L 1}, \ldots, f_{L 4}$ & $0.5,0.2,0.35,0.5$ \\
\hline \multicolumn{2}{|l|}{$\alpha_{\text {Land-ice }}, \alpha_{\text {Sea-ice }}, \alpha_{\text {Land }}$} \\
\hline$\alpha_{\text {Ocean }}, \alpha_{\text {cloud }}$ & $0.9,0.65,0.20,0.07,0.30$ \\
\hline$R, \mathrm{~J} \mathrm{~kg}^{-1} \mathrm{~K}^{-1}$ & 287.04 \\
\hline$C_{p}, \mathrm{~J} \mathrm{~kg}^{-1} \mathrm{~K}^{-1}$ & 1004 \\
\hline$Q_{1}, Q_{2}, Q_{3}, Q_{4}, \mathrm{~W} \mathrm{~m} \mathrm{~m}^{-2}$ & $244,381,381,244$ \\
\hline$P_{1 \mathrm{w} 1}, \ldots, P_{1 \mathrm{w} 4}$ & $0.50,0.53,0.51,0.73$ \\
\hline$K_{\theta}, \mathrm{s}^{-1} \mathrm{~K}^{-2}$ & $15.5 \times 10^{20}$ \\
\hline$K_{M q}, \mathrm{~m}^{4} \mathrm{~s}^{-1} \mathrm{~K}^{-1}$ & $5.4 \times 10^{13}$ \\
\hline$K_{q}, \mathrm{~m}^{3} \mathrm{~s}^{-1}$ & $3.3 \times 10^{8}$ \\
\hline$A, \mathrm{~Pa}$ & $2.53 \times 10^{11}$ \\
\hline$B, \mathrm{~K}$ & $5.42 \times 10^{3}$ \\
\hline
\end{tabular}

of temperature and salinity are balanced by surface fluxes. The equation of state is the full nonlinear equation recommended by the United Nations Educational, Scientific and Cultural Organization (UNESCO; 1981). Under these assumptions, the continuous governing equations become

$$
\begin{gathered}
0=-\frac{1}{\rho_{0}} P_{z}-\frac{g}{\rho_{0}} \rho \\
0=-\frac{1}{\rho_{0}} P_{y}-r v \\
0=v_{y}+w_{z} \\
T_{t}+(v T)_{y}+\left(w T_{z}\right) \\
=K_{h} \Delta T_{y}+K_{v} \Delta T_{z}+\frac{Q_{T}^{\mathrm{atm}}+Q_{T}^{\text {sea }- \text { ice }}}{\rho_{0} C_{\mathrm{pw}} V} \\
S_{t}+(v S)_{y}+(w S)_{z} \\
=K_{h} \Delta S_{y}+K_{v} \Delta S_{z}+\frac{Q_{S}^{\mathrm{atm}}+Q_{S}^{\text {sea }- \text { ice }}}{V} .
\end{gathered}
$$

In the previous equations $(y, z)$ and $(v, w)$ are the (northward, upward) coordinates and velocities; $P$ denotes the pressure; $T, S$ the potential ocean temperature and salinity; $g$ is the gravitational acceleration, and $V$ 
the surface box volume; $\rho_{0}$ is a constant reference water density; $r$ is a friction coefficient. The values $K_{h}$ and $K_{v}$ are the horizontal and vertical diffusion coefficients. ${ }^{1}$ Whenever the vertical stratification is unstable, the vertical diffusion coefficients is made 300 times larger than its value for stable stratification (this larger value gives a mixing time of $1 \mathrm{yr}$ for the upper polar box under unstable stratification. The value for $K_{v}$ in Table 1 is for stable stratification).

The value $Q_{T}^{\text {atm }}$ is the heat flux between the atmosphere and the ocean due to sensible and latent heat and radiative fluxes. A Haney (1971) type parameterization is used for this flux component over open ocean water, and the insulating effect of sea ice of a thickness $D_{\text {sea-ice }}$ is included as well (Walsh 1982), so that

$Q_{T}^{\mathrm{atm}}=\frac{\rho_{0} C_{\mathrm{pw}} D_{\text {upper }}}{\tau}(\theta-T)\left(f_{\text {ow }}+f_{\text {sea-ice }} \frac{\gamma}{D_{\text {sea-ice }}}\right)$,

where $\theta$ is the atmospheric potential temperature and $C_{\mathrm{pw}}$ is the heat capacity of ocean water. Here, $f_{\text {ow }}$ and $f_{\text {sea-ice }}$ are the areas of open water and sea ice cover in the box. The parameter $\gamma$ represents the insulating effect of the sea ice.

The freshwater forcing at the ocean surface is translated into an equivalent salt flux used to drive the ocean salinity equation

$$
Q_{S}^{\mathrm{atm}}=-(P-E) S_{0} A,
$$

where $P-E$ is the precipitation minus evaporation (section $2 \mathrm{~b}$ ), $S_{0}$ is a constant reference salinity, and $A$ represents the box area. For the present study, we modified the model slightly by adding stochastic freshwater fluxes to the four oceanic surfaces boxes. This stochastic freshwater input $\left(\zeta_{1}, \zeta_{2}, \zeta_{3}, \zeta_{4}\right)$ is computed such that the meridionally integrated net freshwater flux is always zero. This leads to the relations $\left[\zeta_{i}(t) \zeta_{j}\left(t^{\prime}\right)\right]=\sigma_{i} \sigma_{j} \delta_{i j} \delta(t$ $-t^{\prime}$ ) for $i, j=1,2,4$. The value $\zeta_{3}$ is computed from $\sum_{i=1}^{4} \zeta_{i} / V_{i}=0$, where $V_{i}$ represents the volume of the $i$ th surface box, $\sigma$ the standard deviation of the freshwater noise and $t$ and $t^{\prime}$ different times. The probability distribution of the noise is chosen to be Gaussian. In order to estimate characteristic values for $\sigma$ we computed the field of standard deviations of annual mean freshwater flux anomalies simulated by the coupled atmospheric general circulation model ECHAM3/LSG (Timmermann et al. 1998). The coupled model is referred to here as CGCM. For simplicity we selected a

\footnotetext{
${ }^{1}$ Note the first-order diffusion terms, which typically arise in box models from an integration of the usual second-order diffusion terms across the box dimension. In the above equations, $\Delta T_{y}$, for example, corresponds to the difference in horizontal derivative of the temperature between the north and south edges of a given box. This implies that the diffusion constants carry also the length scales and hence their units are $\mathrm{m} \mathrm{s}^{-1}$.
}

single characteristic value ${ }^{2}$ for $\sigma$, independent of the latitude (Aeberhardt et al. 2000). According to the central limit theorem the standard deviation of the noise scales with the square root of the averaging time. This relation results in typical model-derived annual mean noise amplitudes of about $0.1-0.2 \mathrm{~Sv}\left(1 \mathrm{~Sv} \equiv 10^{6} \mathrm{~m}^{3}\right.$ $\mathrm{s}^{-1}$ ). Some of our experiments have been repeated using red noise forcing with the same standard deviation, but a damping timescale of 30 days. The results are practically indistinguishable from the white noise forcing simulations.

The heat and equivalent salt fluxes due to the formation or melting of sea ice are given by $Q_{T}^{\text {sea-ice }}$ and $Q_{S}^{\text {sea-ice }}$ in (4), (5). When the temperature of the water in the polar boxes drops below a specified critical temperature, $T^{\text {sea-ice }}$ sea ice is formed. The heat flux available then for the formation of sea ice is calculated using a simple relaxation term using a short timescale $\tau_{\text {sea-ice }}$,

$$
Q_{T}^{\text {sea-ice }}=\frac{\rho_{0} C_{\mathrm{pw}} V_{\text {ocean }}}{\tau_{\text {sea-ice }}}\left(T^{\text {sea-ice }}-T\right),
$$

where $V_{\text {ocean }}$ is the volume of the oceanic box. When the ocean temperature rises above $T^{\text {sea-ice }}$ and sea ice is present, the available heat based on the same expression is used to melt the sea ice. The short timescale used in the sea ice melting (freezing) term ensures that the ocean temperature remains very near (fraction of a degree) to the freezing temperature as long as sea ice is present. Sea ice thus melts (forms) when the ocean temperature is just slightly above (below) the freezing point. The heat flux $Q_{T}^{\text {sea-ice }}$ is converted into the amount of sea ice created or melted, by dividing it by $\rho_{\text {sea-ice }} / L_{f}$ where $\rho_{\text {sea-ice }}$ is the density of sea ice and $L_{f}$ is the latent heat of fusion. The equation for the sea ice volume is therefore

$$
\frac{d\left(V_{\text {sea-ice }}\right)}{d t}=\frac{Q_{T}^{\text {sea-ice }}}{\rho_{\text {sea-ice }} L_{f}}+P_{\text {on-ice }},
$$

where $V_{\text {sea-ice }}$ is the volume of sea ice in the box and $P_{\text {on-ice }}$ is the amount of sea ice buildup due to atmospheric precipitation on the part of the ocean covered with sea ice. Initially, as sea ice starts forming, its thickness is assumed constant (1.5 and $2 \mathrm{~m}$ in the southern and northern polar boxes, respectively) until all the box is covered with sea ice. In order to avoid a full sea ice cover in the Southern Ocean box we have artificially increased the land fraction in the southern box from $20 \%$ to $50 \%$ (see discussion in Gildor and Tziperman 2001). The formation and melting of sea ice in our model also affects the salinity budget (5), through an equivalent salt flux,

\footnotetext{
${ }^{2}$ The reduced coupled atmosphere-ocean model operates on a time step of $6 \mathrm{~h}$. That is why the noise has to be scaled appropriately. We do not modify the numerical scheme, to capture white noise in the most appropriate way (Kloeden and Platen 1992).
} 


$$
Q_{S}^{\text {sea-ice }}=\frac{Q_{T}^{\text {sea-ice }}}{\rho_{\text {sea-ice }} L_{f}} S_{0},
$$

which represents brine rejection due to sea ice formation or freshwater flux due to sea ice melting.

\section{b. Atmospheric model}

The atmospheric model roughly follows those of Marotzke and Stone (1995) and Rivin and Tziperman (1997) and is divided into four vertically averaged boxes, representing the same latitude bands as the upper ocean boxes. The averaged potential temperature of each box is calculated based on the energy balance of the box, taking into account: 1) incoming solar radiation using averaged box albedo calculated according to the relative fraction of each lower surface type in the box, 2) outgoing longwave radiation at the top of the atmosphere, 3) air-sea heat flux, and 4) meridional atmospheric heat transport.

The heat equation in pressure coordinates is $C_{p} T$ $d \ln \theta / d t=Q$, where $Q$ is the heating rate per unit mass and $\theta=T\left(P_{0} / P\right)^{R / C_{p}}$ is the potential temperature at pressure $P$, relative to a reference pressure $P_{0} ; T$ is the air temperature; $R$ is the gas constant for dry air; and $C_{p}$ is the specific heat of the atmosphere at a constant pressure. From the heat equation in pressure coordinates we find $d \theta / d t=\left(1 / C_{P}\right) \theta T^{-1} Q$. Taking the box model potential temperature to represent the potential temperature at $500 \mathrm{mb}$, and letting the reference level be $P_{0}=1000$ $\mathrm{mb}$, we get $\theta / T=2^{R / C_{p}}$ so that $d \theta / d t=2^{R / C_{p}} Q / C_{p}$. Expressing the heating rate as the divergence of a heat flux, $F$, such that $Q=-(1 / \rho) \partial F / \partial y$, integrating the heat equation over the volume of an atmospheric box, we obtain

$$
\begin{aligned}
\frac{\partial \theta}{\partial t}=\frac{2^{R / C_{p}} g}{P_{0} C_{p}} & {\left[\left(F_{\text {Top }}-F_{\text {Surface }}\right)\right.} \\
& \left.+\left(F_{\text {meridional }}^{\text {in }}-F_{\text {meridional }}^{\text {out }}\right)\right] .
\end{aligned}
$$

where $F_{\text {Top }}$ and $F_{\text {Surface }}$ are the heat fluxes at the top of the atmosphere and at the surface, respectively, and where $F_{\text {meridional }}^{\text {in }}-F_{\text {meridional }}^{\text {out }}$ is the net heating due to the meridional heat flux between the atmospheric boxes. Equation (9) is the averaged (over the box area $a$ ) heat balance for a column of air extending from the surface to the top of the atmosphere, with a cross section of 1 $\mathrm{m}^{2}$. Over land and land ice we assume no net heat flux into the surface so $F_{\text {Surface }}$ is only the heat flux between the ocean and the atmosphere, $Q_{T}^{\text {atm }}$.

The value $F_{\text {Top }}$ is composed of the incoming solar radiation $H_{\text {in }}$, between the latitudes $\phi_{1}$ and $\phi_{2}$ that define the atmospheric box boundaries, and the outgoing longwave radiation $H_{\text {out }}$, for a box with a mean potential temperature $\theta$,

$$
\begin{aligned}
F_{\text {Top }} & =H_{\text {in }}-H_{\text {out }} \\
H_{\text {in }} & =\left(1-\alpha_{\text {surface }}\right)\left(1-\alpha_{\text {cloud }}\right) R_{E}^{2} \int_{\phi_{1}}^{\phi^{2}} Q_{\odot} \cos \phi d \phi d \lambda
\end{aligned}
$$

$H_{\mathrm{out}}=P_{l w} \sigma_{B} \theta^{4}$,

where $R_{E}$ is the radius of the earth, $\alpha_{\text {cloud }}$ is a specified constant cloud albedo, and $\alpha_{\text {surface }}$ is the box albedo, which is calculated according to relative fraction and the specified albedo of each surface type $\left(\alpha_{\text {Land }}, \alpha_{\text {Land-ice }}\right.$, $\alpha_{\text {Ocean }}$, and $\alpha_{\text {Sea-ice }}$ for land, land ice, ocean, and sea ice respectively). Here, $Q \odot$ is the solar constant divided by 4; $\sigma_{B}$ is the Stefan-Boltzmann constant and $P_{\mathrm{lw}}$ is an emissivity coefficient that in principle depends on humidity, cloud cover, land cover and topography, aerosol, $\mathrm{CO}_{2}$ concentration, etc., and is therefore allowed here to vary from box to box. The value $P_{\mathrm{lw}}$ is taken here to be constant in time, neglecting temporal variations of atmospheric humidity, $\mathrm{CO}_{2}$ and the aerosol concentrations [see discussion Gildor and Tziperman (2001)].

For the meridional heat transport $F_{\text {meridional }}$ we use (Chen et al. 1995)

$$
F_{\text {meridional }}=K_{\theta} \frac{\partial \theta}{\partial y} .
$$

Rather than using humidity as a prognostic variable, we assume constant relative humidity of 0.7 (Manabe and Strickler 1964), so that $q=0.7 q_{s}$ and the saturation humidity $q_{s}$ at a temperature $T$ is calculated from an approximate Clausius-Clapeyron equation

$$
q_{s}=A e^{B / T} \text {. }
$$

The meridional atmospheric moisture transport, $F_{M q}$, is parameterized as

$$
F_{M q}=K_{M q} \frac{\partial \theta}{\partial y} q,
$$

where $q$ is the humidity of the box to which the humidity flux is directed. [Gildor and Tziperman (2001) and Tziperman and Gildor (2002) discuss in detail the validity of this parameterization.]

Another source of precipitation over the land ice sheets in the polar boxes is local evaporation from the part of the polar box ocean not covered by sea ice (Gildor and Tziperman 2001), parameterized by

$$
F_{q}=K_{q} f_{\text {ow }} q \text {. }
$$

The presence of sea ice significantly reduces this source of moisture, as the fraction of open water ocean, $f_{\text {ow }}$, becomes small.

The total precipitation in a given box is calculated as the convergence of the moisture fluxes $P-E=$ $-\partial\left(F_{M q}+F_{q}\right) / \partial y$. This total precipitation is spread evenly over the box area. We then calculate the fraction falling on sea ice. This fraction is assumed to turn into additional sea ice. 
The dynamic ice sheet model used in Gildor and Tziperman (2001) is not used in our study. Instead we use a constant ice sheet with a volume of $4 \times 10^{16} \mathrm{~m}^{3}$, corresponding to a global sea level change of about 120 $\mathrm{m}$. Furthermore, in order to mimic conditions during the Last Glacial Maximum the atmospheric $\mathrm{CO}_{2}$ concentration was reduced to $200 \mathrm{ppm}$.

\section{Response of the THC to freshwater perturbations}

\section{a. THC hysteresis}

Similar to previous studies (e.g., Ganopolski and Rahmstorf 2001), we perform transient freshwater sensitivity experiments in order to probe the bifurcation structure of our coupled model. The experiments are conducted by increasing the freshwater flux into the northernmost box at a fixed rate $[0.01$ and $0.001 \mathrm{~Sv}$ $(1000 \mathrm{yr})^{-1}$ ] to a maximum value of $0.1 \mathrm{~Sv}$. Subsequently, the freshwater flux is reduced at the same rate until an anomalous value $-0.1 \mathrm{~Sv}$ is attained. Finally an increase in the freshwater flux brings the system back to its initial value. It is evident that these hysteresis diagrams are different from true bifurcation diagrams, which assume an equilibrium forcing, rather than a transient one. A fundamental question then is: how slow do we have to force the model, such that we approximate the bifurcation structure as accurately as possible. In Ganopolski and Rahmstorf (2001) a typical value of $0.01 \mathrm{~Sv}(1000 \mathrm{yr})^{-1}$ for a quasi-equilibrium freshwater forcing rate is suggested that is considered to yield reasonable approximations of the bifurcation structure. However, if the thermohaline circulation undergoes a Hopf bifurcation, as in the case of Sakai and Peltier (1997) or Tziperman et al. (1994) and as we will see later also in our model, this estimate might be invalid, due to the so-called critical slowing down effect. This effect is associated with the real part of the linearized dynamics becoming very small in the vicinity of a Hopf bifurcation. This implies that transients (deviations from the real equilibrium solution) will not be damped sufficiently, thereby delaying the approximation of the transient field to the equilibrium field. Furthermore, even the position of the saddle-node bifurcation depends strongly on the rate of the freshwater forcing, and theoretical studies by Berglund and Kunz (1999) and Berglund and Gentz (2002) reveal that certain scaling laws exist that characterize the deviations between a transient simulation and the true bifurcation diagram. In order to study this effect, we have forced our model with different freshwater perturbation rates $[0.01 \mathrm{~Sv}(1000$ $\mathrm{yr}^{-1}$, as in Ganopolski and Rahmstorf (2001) and 0.001 Sv $(1000 \mathrm{yr})^{-1}$ ]. The results are shown in Fig. 1 (left). We clearly see that the critical point of the saddle-node bifurcation moves from right to left as we go from fast to slow forcing. Furthermore, fast forcing is associated with the existence of a THC flush near zero freshwater flux. This flush is generated as a response to a long phase of a weak THC. During this phase vertical diffusion warms the deep ocean and the heat can be released to the surface by a THC flush, once the deep ocean density is less than the surface ocean density. These flushes represent the transient behavior of the hysteresis experiment, rather than the true bifurcation structure. Similar structures can be found in the hysteresis diagrams of Ganopolski and Rahmstorf (2001).

Accounting for additional stochastic freshwater pulses with an amplitude of $0.06 \mathrm{~Sv}$, which is somewhat less than the typical value of $0.1-0.2 \mathrm{~Sv}$ derived from the CGCM simulation ${ }^{3}$ gives birth to a new phenomenon, which is absent in the deterministic run. As can be seen from Fig. 1 (right), the stochastically forced hysteresis diagram shows oscillations, which can attain amplitudes of up to $8 \mathrm{~Sv}$. The typical timescales of these oscillations is a few centuries up to a few millennia. This effect is consistent with the finding of Ganopolski and Rahmstorf (2002) who demonstrate that their climate model of intermediate complexity exhibits coherence resonance (CR) when forced stochastically. Coherence resonance can be explained in terms of a noisy precursor to deterministic bifurcations such as Hopf bifurcations (Neiman et al. 1997) or homoclinic and heteroclinic bifurcations (Stone and Holmes 1989; Stone and Armbruster 1999). This effect will be discussed in more depth in section 5 .

\section{b. Meltwater pulse without noise}

The importance of freshwater pulses in determining the strength of the THC has long been realized. Several prominent pulses can be identified during the last glacial period. They were most likely associated with instabilities of the Laurentide ice sheet. At the millenial timescale Marshall and Clarke (1999) using a coupled icesheet-hydrology model estimated typical freshwater fluxes into the subtropical and subpolar North Atlantic with amplitudes of around $0.2-0.6 \mathrm{~Sv}$. Typical durations were a few hundred years.

In order to isolate important climate feedbacks that contribute to the (de)stabilization of the THC, we study the sensitivity of our coupled model under Last Glacial Maximum (LGM) conditions to meltwater pulses. Freshwater anomalies of different magnitudes $(0.075$, 0.3 , and $0.45 \mathrm{~Sv}$ ) are injected for $300 \mathrm{yr}$ into the northernmost oceanic box.

The simulated time series for the North Atlantic transport are shown in Fig. 2a. It can be seen that both recovery time and induced transport anomaly depend strongly on the magnitude of the freshwater forcing. In

\footnotetext{
${ }^{3}$ This difference accounts for the fact that in the simplified model the whole North Atlantic box is subjected to convection changes once a freshwater forcing is applied, whereas in the CGCM only a few key sites (south of Greenland and in the Greenland-Iceland-Norwegian Sea) respond to changes in freshwater forcing.
} 

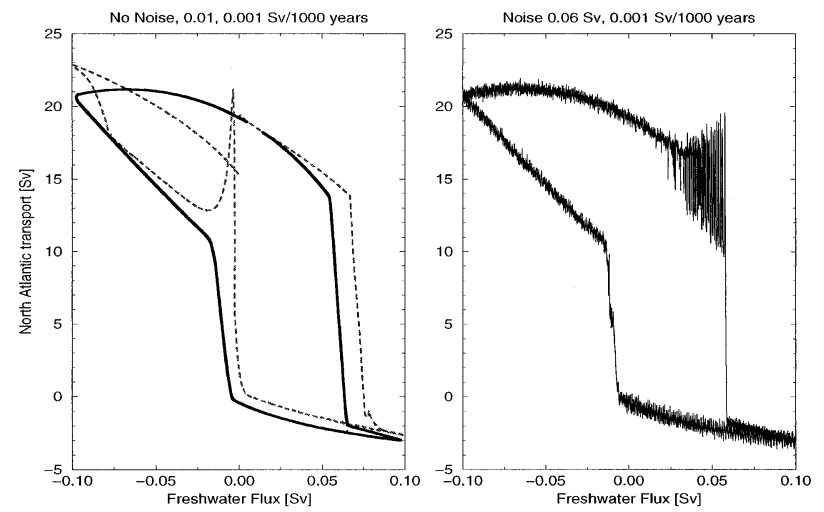

FIG. 1. Solid lines show North Atlantic transport as a function of slowly modified freshwater flux (left) without stochastic forcing and (right) with a stochastic freshwater component with an amplitude of $0.06 \mathrm{~Sv}$. Transient simulations are performed in which the freshwater flux is changed linearly at a rate of $0.001 \mathrm{~Sv}(1000 \mathrm{yr})^{-1}$. Dashed line at left shows transient simulations performed in which the freshwater flux is changed linearly at a rate of $0.01 \mathrm{~Sv}(1000 \mathrm{yr})^{-1}$.

our model configuration, a 300-yr-long perturbation with an amplitude of $0.45 \mathrm{~Sv}$ is sufficient to shut down the North Atlantic THC for a few centuries. Comparable shutdown periods were also found by Sakai and Peltier (1996). During the shutdown, both the vertical density gradients in the North Atlantic as well as the meridional density gradients within the North Atlantic are zero. This implies that the THC operates beyond the convective and advective thresholds. The THC recovers quickly, due to convective heating of the subsurface ocean and a subsequent destabiliziation of the northernmost Atlantic water column. In cases of small to moderate freshwater perturbations the THC recovers completely, whereas in the strong perturbation case the THC equilibrates at a new transport level of about 9 Sv.

\section{c. Meltwater pulse and noise}

We repeated these experiments, with an additional stochastic freshwater forcing applied to the oceanic surface boxes. In this case the annual mean value for the stochastic freshwater forcing amplitude amounts to 0.06 Sv. The resulting time series of the THC are shown in Fig. 2 (right). We observe that the qualitative behavior differs significantly from the deterministic meltwater experiments: after a 300-yr-long meltwater pulse with an amplitude of $0.45 \mathrm{~Sv}$, an oscillation is excited that is absent in the deterministic simulation. The timescale of this oscillation is about $1600 \mathrm{yr}$ and it involves THC fluctuations of approximately $8 \mathrm{~Sv}$. These experiments reveal that freshwater injections of sufficient amplitude, together with an appropriate freshwater noise level trigger millennial-scale oscillations in our model.

The millennial-scale climate transitions simulated by the stochastic meltwater experiments are further investigated by studying other physical quantities in the high-
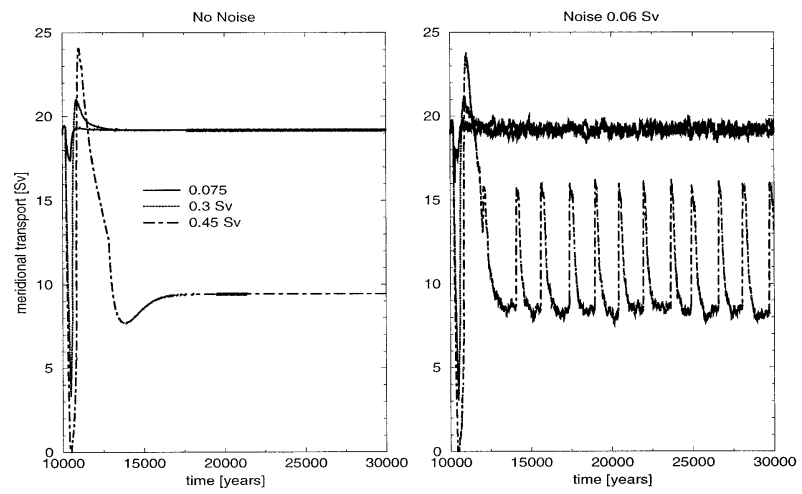

FIG. 2. Response of the North Atlantic transport to a 300-yr-long North Atlantic meltwater pulse of varying amplitude $(0.075,0.3$, and $0.45 \mathrm{~Sv}$ ). The pulse starts in year 10000 . (left) Without stochastic forcing, (right) with stochastic forcing of 0.06-Sv amplitude.

latitude atmospheric and oceanic boxes. From Fig. 3 we see that millennial-scale oscillations of the THC, as depicted in Fig. 2, are accompanied by dramatic atmospheric temperature changes. Figure 3 a reveals that the temperature in the northernmost atmospheric box undergoes rapid transitions from a very cold state to relatively warm temperatures within less than $20 \mathrm{yr}$. The January temperature range between "coldest" and "warmest" state amounts to about $-43^{\circ}$ to $-13^{\circ} \mathrm{C}$. The temperature range of annual mean data amounts to about $-17^{\circ}$ to $-3^{\circ} \mathrm{C}$ and agrees favorably with stadial-interstadial temperature differences reconstructed from the Greenland summit ice cores (Severinghaus and Brook 1999; Lang et al. 1999). The rapid warmings are followed by a slow cooling phase. The similaritiy with the general pattern of the observed shorter Dansgaard-Oeschger cycles is apparent. These rapid atmospheric warmings are associated with spikes in the oceanic surface temperature in the northern box (not shown). Such spikes are related to strong convective events that vent accumulated subsurface heat to the surface (see Fig. 3b). This leads to the melting of sea ice (Fig. 3d.) and the release of freshwater into the high-latitude oceanic box. Eventually, the THC reduces and a polar halocline builds as can be seen from the surface and subsurface density time series in Fig. 3c. Slowly, due to diffusive processes, the subsurface temperatures increase in the North Atlantic (Fig. 3b). Once a buoyancy and, hence, a vertical density gradient threshold value is exceeded (see Figs. 3b,c), convection occurs suddenly and the subsurface heat is vented again to the surface, thereby closing one cycle. The characteristic timescale is determined by the time diffusive processes need to destabilize the polar halocline from below and another characteristic time that depends, among other factors, on the noise level.

The scenario described above bears many similarities to the flip-flop oscillations discussed by Welander (1986) and Pierce et al. (1995) and the deep-decoupling mode described by Winton (1993). In our simulations 

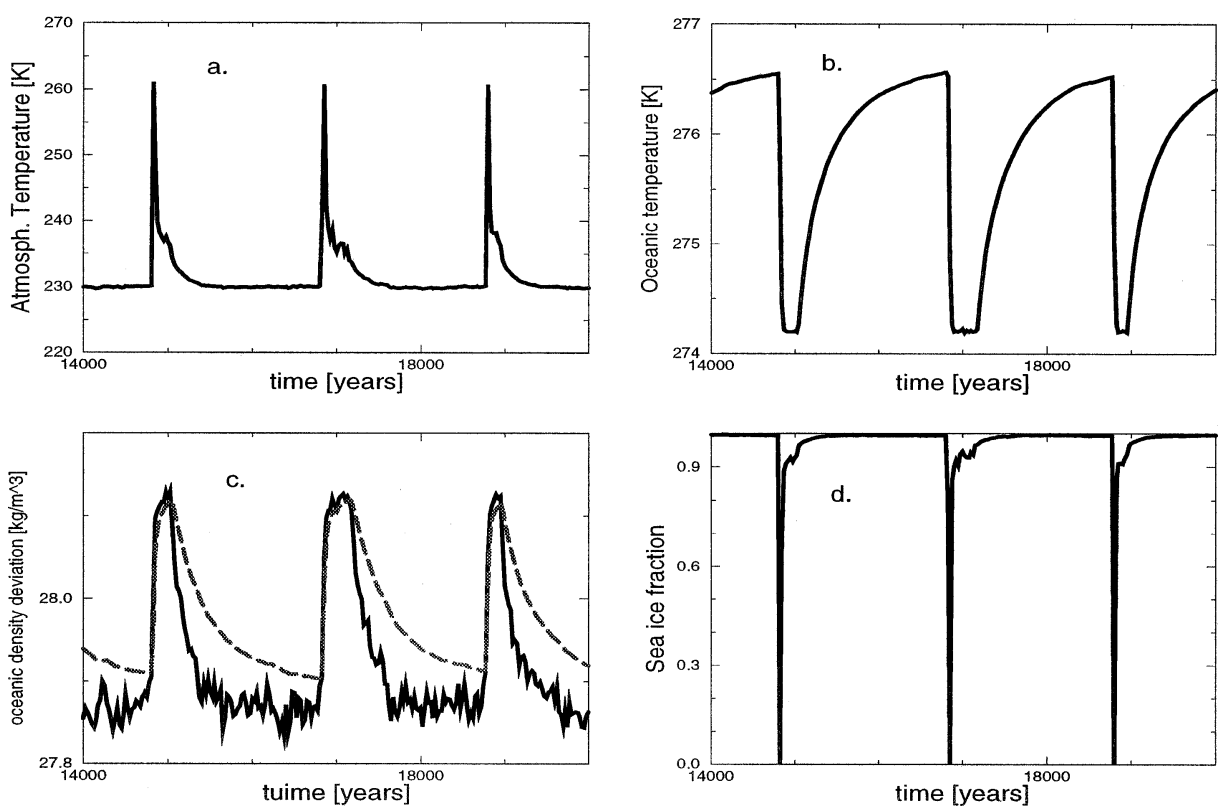

FIG. 3. Jan atmospheric and oceanic variables corresponding to the stochastically forced meltwater experiment in Fig. 2 using a maximum freshwater anomaly of 0.45 Sv. (a) Atmospheric temperature, (b) oceanic subsurface temperature, (c) surface (solid) and subsurface (dashed) density, and (d) sea ice fraction in the northernmost box.

sea ice plays an important role in that it provides a negative feedback (Paul and Schulz 2002) to the abrupt strengthening of the North Atlantic THC. This has been shown by performing a set of sensitivity experiments (not shown) for which the sea ice fraction and depth are assumed to be constant. In none of these experiments was a millennial-scale oscillation observed using the same stochastic and meltwater forcings as described earlier.
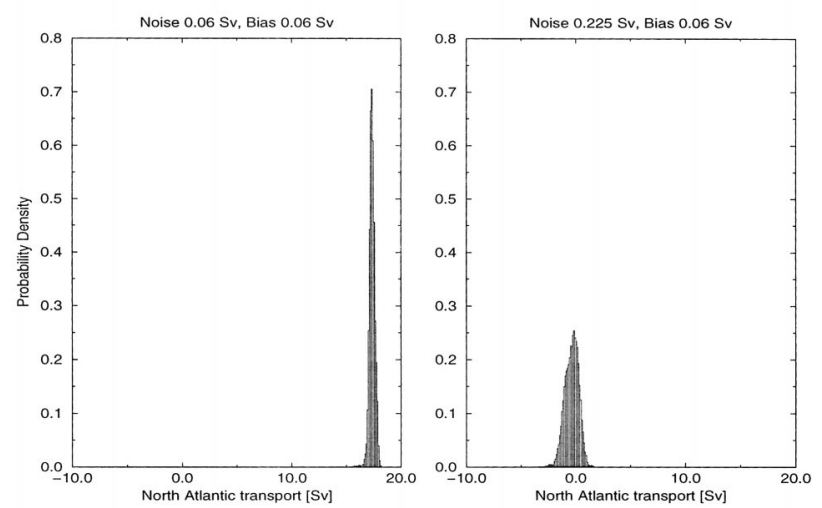

FIG. 4. Probability distribution of the North Atlantic transport for two different values of the freshwater noise (left) $0.06 \mathrm{~Sv}$ and (right) $0.225 \mathrm{~Sv}$. A mean freshwater forcing of $0.06 \mathrm{~Sv}$ is applied, such that the system can operate close to the saddle-node bifurcation.

\section{Noise-induced transitions}

Recently, Timmermann and Lohmann (2000) and Monahan et al. (2002) proposed a new mechanism for the destabilization of the THC. It was suggested that stochastic buoyancy fluxes can lead to a destabilization of the THC. In these studies the Stommel (1961) box model was used in order to investigate how the inclusion of noise affects the stationary modes of the THC. It turned out that above a certain noise threshold for the buoyancy fluxes, a collapse of the THC can be induced by increasing the amplitude of the stochastic fluctuations. This nonlinear effect can be understood in terms of the concept of noise-induced transitions (NIT). Generally, a NIT occurs when the inclusion of a sufficient amount of noise modifies the structure of the stationary probability distribution qualitatively.

Here, we study whether the proposed concept of NIT applies also to more complicated climate models such as the one used here. Instead of modifying temperature noise, as in Timmermann and Lohmann (2000), we change the level of the annual mean freshwater noise $\sigma$ from 0.06 to $0.225 \mathrm{~Sv}$ around a mean freshwater forcing of $0.06 \mathrm{~Sv}$. We transformed the timeseries for the simulated North Atlantic transports into normalized histograms.

For small noise levels (see Fig. 4) we observe a narrow probability distribution centered around a stationary THC transport state of $\sim 17 \mathrm{~Sv}$. It becomes broadened and bimodal for intermediate noise levels (not shown). For large noise amplitudes of around $0.225 \mathrm{~Sv}$ the prob- 

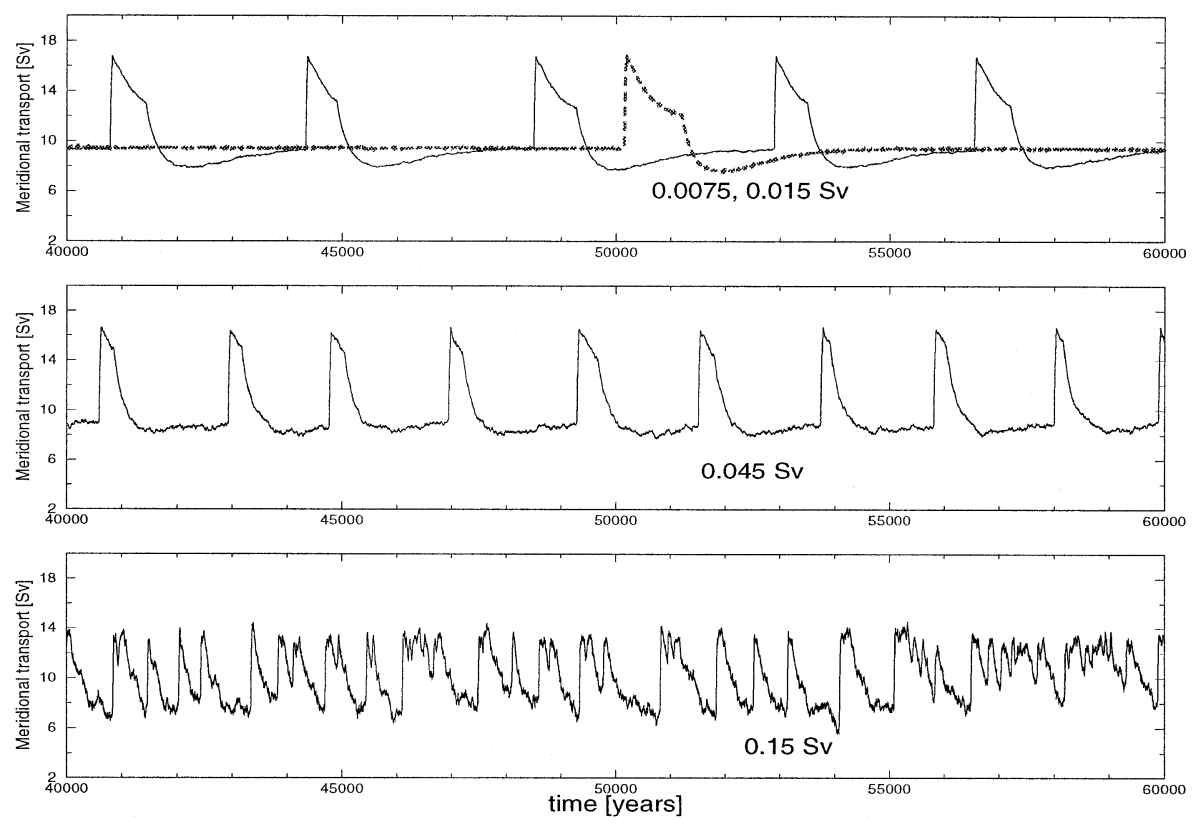

FIG. 5. Response of the North Atlantic transport to stochastic freshwater forcing with different amplitudes: (top) 0.075 (dashed) and $0.015 \mathrm{~Sv}$; (middle) $0.045 \mathrm{~Sv}$; and (bottom) $0.15 \mathrm{~Sv}$.

ability distribution exhibits an abrupt qualitative change: The probability distribution flips from a bimodal regime to a unimodal regime, which is characterized by a collapsed THC state. Summarizing, we found that the qualitative structure of the probability distribution function (PDF) depends crucially on the noise level, thereby supporting the idea of Timmermann and Lohmann (2000) that noise can be an important agent in rectifying qualitatively the probability distribution of the THC. Changes in the noise level that might be linked to the intensity of the hydrological cycle trigger transitions between a present-day stationary THC state, an oscillatory stadialinterstadial regime, and a Heinrich state with collapsed THC.

\section{Noise-induced oscillations: Coherence resonance}

The hysteresis diagram in Fig. 1 already revealed the existence of noise-induced millennial-scale oscillations. Here we will study these oscillations and their stochastic excitability more in detail. Figure 5 shows simulated time series for the North Atlantic transport for different noise levels $(0.0075,0.015,0.045$, and $0.15 \mathrm{~Sv})$. The simulations were started like the meltwater experiments in Fig. 2 with a 300-yr-long meltwater pulse with an amplitude of $0.45 \mathrm{~Sv}$. For small noise amplitudes we observe a stationary transport solution that attains values of about $10 \mathrm{~Sv}$ (see Fig. 2). Increasing the noise level leads to a qualitative dynamical change. For an annual noise level of about $\sigma=0.0075 \mathrm{~Sv}$, the coupled climate system starts to oscillate with a period of about 30000 yr (Fig. 5, top). As will be shown later the period can be decomposed into a stadial part, which is strongly dependent on the noise level, and an interstadial part that is rather insensitive to the noise amplitude and is largely governed by diffusive processes. Increasing the noise level to values of $0.015,0.045$ and $0.15 \mathrm{~Sv}$ (Fig. 5) leads to a dramatic reduction of the period. It is reduced from multimillennial timescales to centennial timescales for the given range of noise levels. It should be noted here that both the critical noise level as well as the simulated low-noise probability distribution and the frequency characteristics depend also on the intensity of the initial meltwater pulse. This can be explained from the hysteresis diagram in Fig. 1. For small meltwater pulses the system remains left of the Hopf bifurcation. Noise forcing in that case probes the Hopf bifurcation from left to right. For larger meltwater pulses the system stays close to the saddle-node bifurcation and the millennial-scale limit cycle. The no-noise 10$\mathrm{Sv}$ state of the thermohaline circulation in the previous experiments led us thus to the conclusion that it actually corresponds to an oscillation with almost infinite period, a so-called homoclinic orbit. Thus the behavior shown in Fig. 5 can be understood in terms of noise probing the existence of a homoclinic bifurcation. Furthermore, these experiments suggest that there is an optimal noise level, which corresponds to the highest degree of regularity of the THC oscillations (see Fig. 5). Similar sensitivities with respect to the noise characteristics have been observed for other dynamical systems such as the stochastically excited FitzHugh-Nagumo system (Lindner and Schimansky-Geier 1999, 2000) that mimics the regenerative firing behavior in an excitable nerve cell. Lindner and Schimansky-Geier (1999) discuss a case in which oscillatory behavior is induced by stochastic forc- 
ing. A sufficient amount of stochastic noise induces a regular, oscillatory regime. An exaggerated input of noise washes out the periodic oscillation and leads to a random output. This delicate balance between noise and nonlinear dynamics is known as autonomous stochastic resonance (Gang et al. 1993; Longtin 1997) or coherence resonance (Pikovsky and Kurths 1997; Lindner and Schimansky-Geier 1999; Pradines et al. 1999). Coherence resonance can be explained in terms of a noisy precursor to deterministic bifurcations such as Hopf bifurcations (Neiman et al. 1997) or homoclinic and heteroclinic bifurcations (Stone and Holmes 1989; Stone and Armbruster 1999). One of the main features of this dynamical systems' concept is that stochastic forcing that acts upon nonlinear excitable systems induces a new nondeterministic timescale similar to the one identified in our stochastic sensitivity experiments. Typical deterministic recovery times on the other hand such as timescales characterizing relaxations into fixed points (interstadial-stadial transitions) are only slightly affected by random perturbations.

Summarizing, our coupled climate model exhibits all typical features of CR when subjected to noise. This coherence resonance probes the Hopf bifurcation for small initial meltwater pulses and a homoclinic bifurcation (merger between the millennial-scale limit cycle and the saddle node) for larger meltwater pulses.

\section{Nonautonomous stochastic resonance}

It has been suggested in a series of recent papers (Alley et al. 2001; Ganopolski and Rahmstorf 2002) that noise might provide a mechanism to amplify weak periodic millennial-scale climate signals. This nonlinear amplification mechanism is called stochastic resonance (SR; Benzi et al. 1981, 1982; Nicolis 1982; Gammaitoni et al. 1998). To put it in more general terms, stochastic resonance describes the synchronization between noiseinduced fluctuations and weak periodic forcing in nonlinear systems. The mechanism SR is characterized by a nonlinear signal-to-noise ratio. Here we study the response of the coupled climate model to the combined effect of stochastic and periodic buoyancy forcing. We apply a sinusoidal forcing with a period of $1500 \mathrm{yr}$. It is important to note that we are not dealing with the classical SR case, but rather with a nontrivial complication, which arises from the fact that our system is an excitable system rather than a typical multistable system and exhibits SR characteristics even without external forcing. Similar cases are dealt with in Lindner and Schimansky-Geier (2000). Further inclusion of periodic forcing modifies the autonomous SR characteristics quantitatively but not qualitatively.

We perform several coupled experiments in which an external periodic freshwater forcing with an amplitude of $0.01 \mathrm{~Sv}$ is added to the northernmost oceanic box. The experiments are initialized as in Fig. 2.

Figure 6a depicts the simulated transport for an ex-
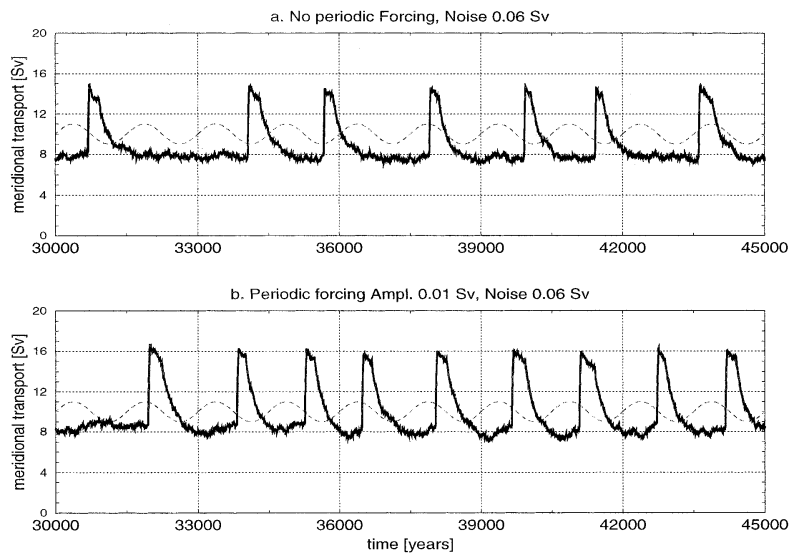

FIG. 6. Response of the thermohaline circulation to periodic freshwater forcing (thin dashed line, not to scale), with a period of 1500 $\mathrm{yr}$ and different amplitudes of (a) $0 \mathrm{~Sv}$ and (b) $0.01 \mathrm{~Sv}$. A stochastic forcing with an amplitude of $0.06 \mathrm{~Sv}$ is also applied. [The thin dashed line in (a) is for reference only.]

periment without external periodic forcing. The transport is the same as in Fig. 2. For reference purposes a $1500-y r$ periodic signal is also shown. We observe that the millennial-scale variability is not periodic in the strict sense. The return time of stadial-interstadial transitions is distributed statistically. The meridional transport simulated by the periodically forced experiment is shown in Fig. 6b. The millennial-scale stadial-interstadial transitions are locked to a certain phase of the external forcing (dashed line). The amplitude of the oscillation as well as their shape is not affected by the periodic forcing. Here we see a typical phase synchronization phenomenon (Rosenblum et al. 1996) between a coherent resonant oscillation and an external pacemaker. This is a more complicated situation than the classical SR concept, which is based on the idea of multiple stationary equilibria. The situation here originates from an interaction between autonomous and nonautonomous SR. The data shown in Figs. 6a,b are very similar to results presented in the paper by Ganopolski and Rahmstorf (2002). Hence, we speculate that also in their case, a similar interaction between a stochastically excited internal ocean oscillation (autonomous SR) and an external forcing (nonautonomous SR) is present.

\section{The Bond cycle: A coupled ocean-cryosphere oscillation}

In the introduction we mentioned that massive meltwater pulses such as Heinrich events (Heinrich 1988; Bond et al. 1992, 1993) play an important role in the context of millennial-scale climate variability during the last glacial period. Hence, we will study the role of episodic long-term meltwater forcing on the generation of millennial-scale variability. A set of experiments was performed in which Heinrich events are mimicked by periodic freshwater pulses with 0.15 and $0.45 \mathrm{~Sv}$ am- 

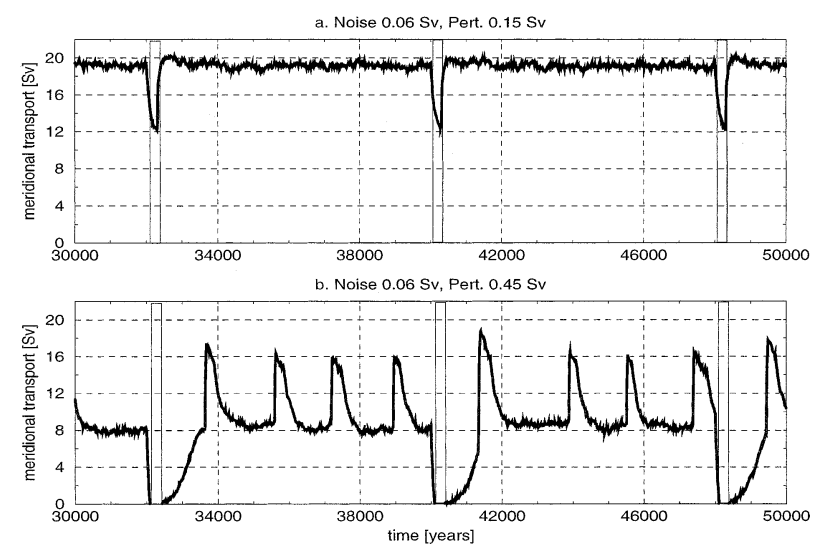

FIG. 7. Response of the North Atlantic transport to periodically occurring 300-yr-long North Atlantic meltwater pulses (vertical bars) of varying amplitudes of (a) $0.15 \mathrm{~Sv}$ and (b) $0.45 \mathrm{~Sv}$. A stochastic forcing with an amplitude of $0.06 \mathrm{~Sv}$ is applied.

plitude. The duration of these sawtoothlike pulses 4 is chosen to be $300 \mathrm{yr}$ and their periodicity is $8000 \mathrm{yr}$, resembling approximately the spacing between subsequent Heinrich events (e.g., Sarnthein et al. 2001). Furthermore, the oceanic boxes are subjected to a stochastic freshwater component of $0.06 \mathrm{~Sv}$ amplitude. The response of the THC to these pulses is shown in Fig. 7. Small externally prescribed Heinrich events lead to a reduction of the THC by $7 \mathrm{~Sv}$. The small events are characterized by a quick recovery to normal THC conditions. However, large Heinrich events can generate millennial-scale oscillations with timescales of about $1500 \mathrm{yr}$. In the paleoclimatic context this could be an indication that Heinrich events can trigger DansgaardOeschger events.

An important question to be addressed then is: If DO cycles were in fact excited by Heinrich events, why do Heinrich events in the observational record (Bond and Lotti 1995) occur in a stadial phase. It appears as if the occurrence of Heinrich events is also synchronized with packages of DO cycles. This interaction scenario has been discussed in a recent study by Schulz et al. (2002) using a three-box ocean model and a conceptual anomalous ice sheet model. Here, we will follow these ideas about a coupled millennial ocean-cryosphere mode by studying the synchronization between the simulated DO cycles and the surging behavior of a conceptual anomalous ice sheet model, that captures the part of the ice sheet that is involved in Heinrich events. The growth rate of the anomalous ice sheet is assumed to be climate dependent. The anomalous ice sheet grows at a rate of $8 \times 10^{14} \mathrm{~m}^{3}(8000 \mathrm{yr})^{-1}$ in cases where the North Atlantic transport is weaker than $13 \mathrm{~Sv}$. Its growth rate is assumed to be 5 times smaller in cases where this transport threshold is exceeded. This asymmetric growth rate captures qualitatively the climate-dependent ice growth

${ }^{4}$ Our results are not sensitive to the particular shape of the forcing. as simulated by the dynamic ice sheet model of Marshall and Clarke (1999). Furthermore, we assume a relationship between the anomalous ice volume $V_{a}^{\text {ice }}$ and an anomalous freshwater supply $F_{a}$ for the Northern Hemisphere which reads $F_{a}=V_{a}^{\text {ice }} /\left(3 \times 10^{16}\right) \mathrm{Sv} \mathrm{m}^{-3}$. If the volume of the anomalous ice sheet exceeds $3.05 \times 10^{15}$ $\mathrm{m}^{3}$, equivalent to a sea level rise of about $10 \mathrm{~m}$ (see Lambeck and Chappell 2001), the anomalous ice volume melts within $300 \mathrm{yr}$, thereby providing an extra $0.32 \mathrm{~Sv}$ freshwater forcing for the ocean. The effect of the simulated coupling between the anomalous conceptual ice sheet and our coupled climate model is depicted in Fig. 8.

We observe that during the relatively long stadials the ice sheet grows rapidly, whereas it is strongly reduced during the short interstadial events. The ice sheet accumulates ice and within about $8500 \mathrm{yr}$ the threshold value is reached. As in the MacAyeal (1993a) ice sheet model, a surge is initiated once a stability threshold of the ice sheet is exceeded. This leads to the generation of a Heinrich event and a subsequent collapse of the thermohaline circulation. During the Heinrich event heat is accumulated in the subsurface ocean due to diffusive processes. As a result the density in the deep ocean is decreased and a convective flush is triggered when surface and subsurface density are equal. This kicks off another deep decoupling cycle, which furthermore leads to a new buildup of the anomalous ice sheet. Our results support the phase-synchronization hypothesis proposed by Schulz et al. (2002) who used a much simpler oceanice-sheet model than used here in this study.

\section{Role of ocean diffusion}

We have already mentioned that the return timescale of DO events can be decomposed into a stochastic contribution, which mainly controls the length of stadials, and a deterministic diffusive contribution, which mostly affects the length of the interstadial events. The importance of ocean diffusion for long-term climate variations and the stability of the THC has been pointed out, for example, by Wright and Stocker (1991), Sakai and Peltier (1999, 2001) and Zhang et al. (1999). We study the dependence on the horizontal and vertical diffusion coefficients $\left(K_{h}, K_{v}\right.$ by repeating the coupled icesheet-climate system experiments of the previous section by multiplying the standard vertical and horizontal diffusivities each by factors of 0.3 and 1.8. The result is shown in Figs. 9a,b. For small horizontal diffusion (Fig. 9b) no DO oscillations are excited. Furthermore, we see that the fate of the THC in the aftermath of a Heinrich event depends strongly on the vertical diffusivity. In contrast to the large vertical diffusion case, small vertical diffusivity leads to a very slow buildup of heat in the deep ocean, thereby preventing quick flushes. In Fig. 9a the meridional transport is displayed for a horizontal diffusivity that is 1.8 times larger than the standard values in Table 1 . Both the occurrence of 

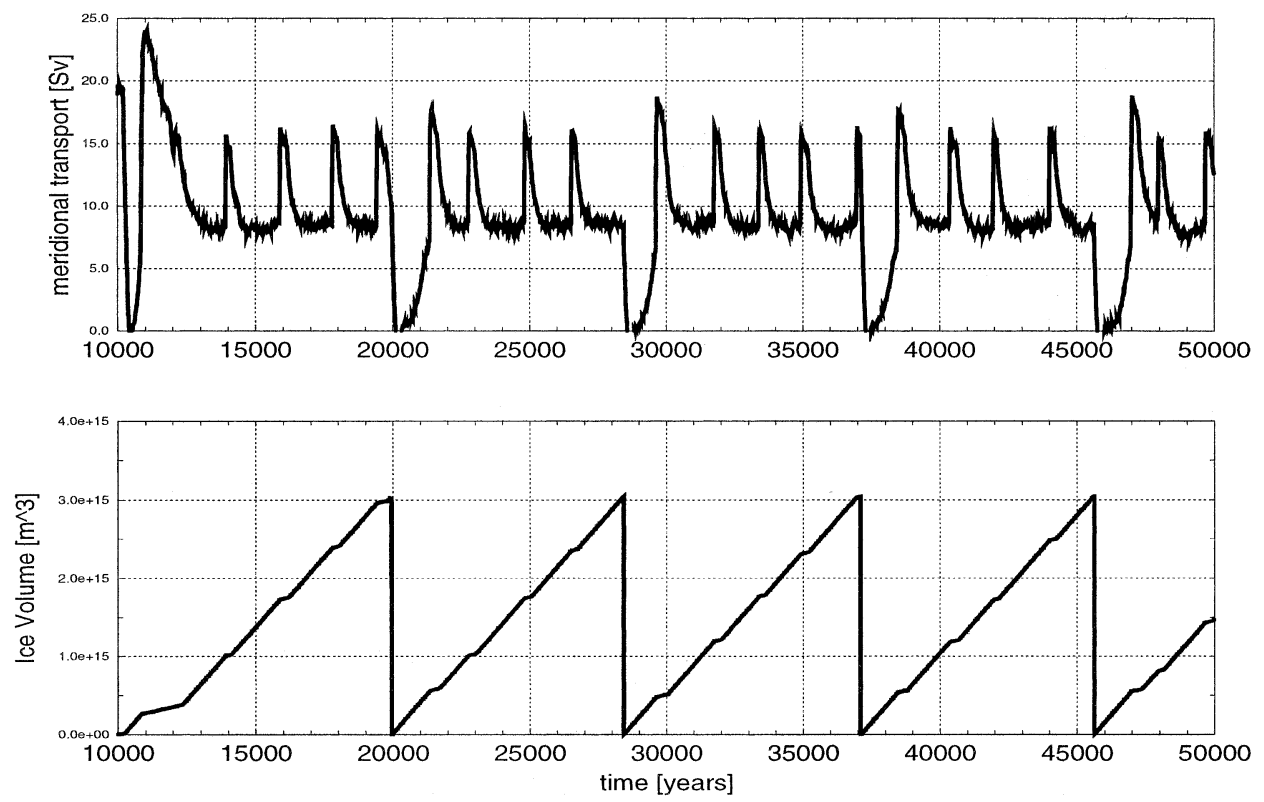

FIG. 8. Response of the thermohaline circulation and the anomalous ice sheet to an initial 300-yr-long meltwater pulse in the North Atlantic with an amplitude of $0.45 \mathrm{~Sv} ; 300$-yr-long Heinrich events are generated once the ice sheet exceeds a critical volume of $3 \times 10^{15} \mathrm{~m}^{3}$. A stochastic forcing with an amplitude of $0.06 \mathrm{~Sv}$ is also applied. The ice growth rate depends on the state of the THC.
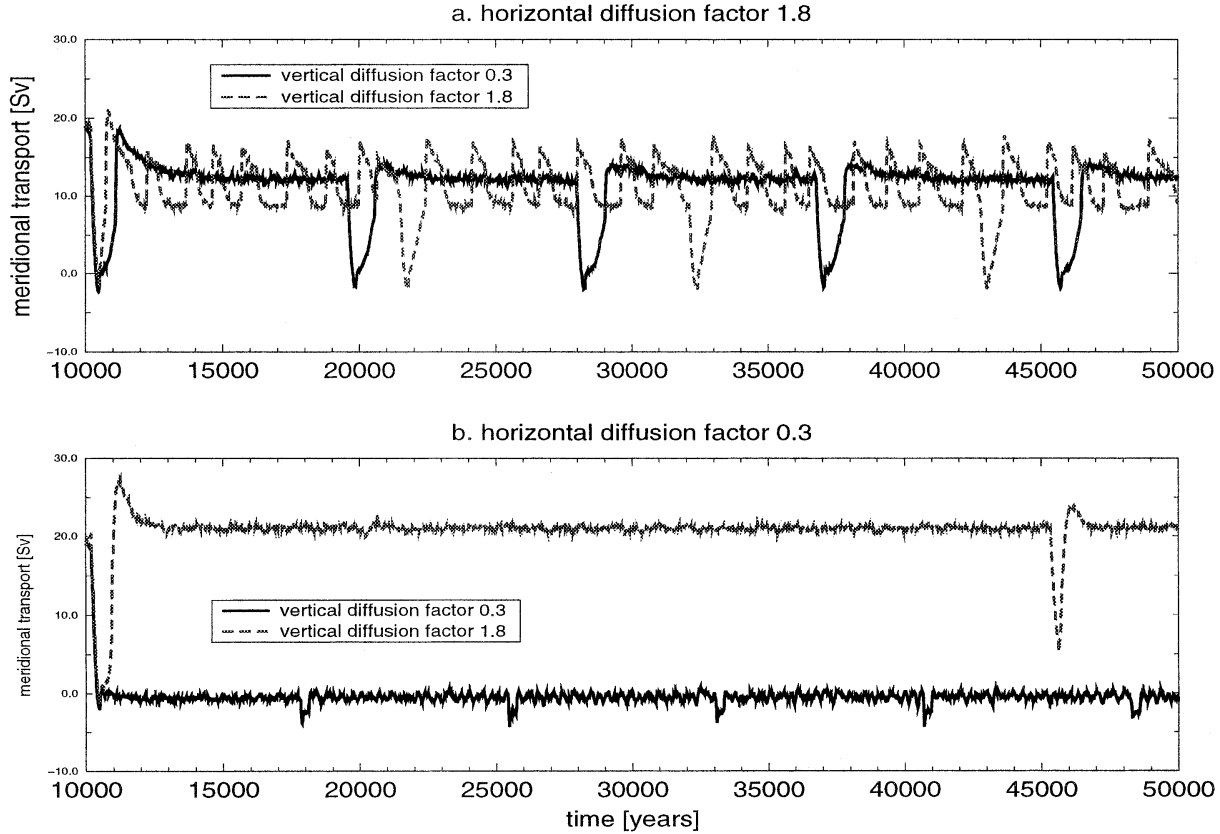

FIG. 9. Response of the thermohaline circulation to an initial 300-yr-long meltwater pulse in the North Atlantic with an amplitude of $0.45 \mathrm{~Sv}$ for different horizontal and vertical diffusion coefficients; 300yr-long Heinrich events are generated once the ice sheet exceeds a critical volume of $3 \times 10^{15} \mathrm{~m}^{3}$. A stochastic forcing with an amplitude of $0.06 \mathrm{~Sv}$ is also applied. (a) The standard horizontal diffusion coefficients (see Table 1 ) were multiplied by 1.8. Two vertical diffusion factors are chosen $(0.3$ and 1.8 ). (b) The same as in (a) but multiplied by 0.3 . Two vertical diffusion factors $(0.3$ and 1.8$)$ were chosen. 
DO cycles as well as the period of Heinrich events (the Bond cycle) depend strongly on the vertical diffusivity. Hence, the period of the millennial-scale oscillations (DO and Bond cycles) can be decomposed into a stochastic component and a deterministic component due to horizontal and vertical diffusion. ${ }^{5}$

\section{Discussion}

We studied the generation of millennial-scale climate variability in the Northern Hemisphere using a loworder coupled climate model. Experiments were conducted in which the model was subjected to additional stochastic freshwater forcing in all oceanic surface boxes and freshwater perturbations in the northernmost box. It turned out that millennial-scale oscillations, resembling observed DO variations in their general pattern, ${ }^{6}$ are excitable by freshwater noise, once the high-latitude oceanic boxes are sufficiently freshened (see Fig. 1). Translated to the paleoclimatic record this may help us understand why DO cycles were active after Heinrich events (enormous meltwater pulses triggered by ice sheet instabilities) that resulted in sea level changes of up to $15 \mathrm{~m}$ (Lambeck and Chappell 2001). Note that this freshwater forcing has to be interpreted in terms of a sufficient, not a necessary condition. We do not deny the possibility that a series of DO events may be kicked off without appropriate freshwater forcing. This might be particularly true for the early interstadials 22, 21, and 20 seen of the Greenland Ice Sheet Project 2 (GISP2) ice core (Stuiver and Grootes 2000).

One of the key results of our paper with important consequences for the interpretation of paleoclimatic data is the following: We hypothesize that DO events are the joint result of stochastic freshwater forcing and Heinrich events. This leads to a simple explanation of the fact that DO oscillations are preceded by Heinrich events (Bond and Lotti 1995; Alley 1998): A Heinrich event mimicked here by a meltwater pulse kicks off a series of Dansgaard-Oeschger cycles, which transport part of the initial freshwater anomaly southward. The next Heinrich event resets the cycle and a new series of Dansgaard-Oeschger events is excited stochastically. Based on these results we can easily explain the absence of Dansgaard-Oeschger events during the Holocene: Ice sheet meltwater surges in the category of Heinrich events were simply impossible during the Holocene because of the absence of the Laurentide ice sheet. Furthermore, the sea ice feedback, essential for our oscillations is less efficient in warm climates.

We have not yet discussed the possible origin of Heinrich events. Several studies (e.g., Alley and MacAyeal 1994; MacAyeal 1993a,b; Marshall and Clarke 1997)

\footnotetext{
${ }^{5}$ This situation resembles closely the situation of a stochastically perturbed homoclinic-heteroclinic orbit discussed in Stone and Armbruster (1999).

${ }^{6}$ Given the simplicity of our coupled model.
}

have come to the conclusion that Heinrich events can be generated by internal ice sheet dynamics in conjunction with processes allowing for fast ice-surging instabilities. Ice stream surging processes (MacAyeal 1993a,b), the rapid breakup of ice shelves (Hulbe 1997), as well as tidewater instabilities (Clarke 1987) have been proposed to account for rapid and massive iceberg surges. Still the question remains as to whether Heinrich events are internal ice sheet oscillations or whether they are coupled to the DO cycles. Based on our results we favor the latter possibility: During stadials relatively cold conditions in high latitudes might have led to the increase of ice accumulation (reduced melting) over the Northern Hemisphere and the subsequent growth of the Laurentide ice sheet (Marshall and Clarke 1999). Also, during the stadials even more ice accumulates on top of the ice sheet. Both mechanical and thermodynamical instabilities can lead to a surge, once critical thresholds are exceeded. The resulting new Heinrich event kicks off another set of Dansgaard-Oeschger cycles. The DO and Heinrich mode operate in a coupled tandem mode. Though there is only conceptual modeling evidence from our coupled climate model and a previous study (Schulz et al. 2002), this coupled Heinrich-DansgaardOeschger mode might serve as a unifying interpretation of Bond cycles. This possibility will be studied in forthcoming work using dynamic ice sheet models.

The millennial-scale DO cycles discussed in our paper can also be interpreted in the light of dynamical systems' analysis. They have to be distinguished from stochastically excited linear oscillations. Deterministic oscillations, or limit-cycle dynamics already possess eigenfrequencies, whereas in our case the deterministic equations with standard parameters do not exhibit any oscillations in the absence of noise. Hence, we are dealing with an excitable system, which is characterized by a very remarkable feature: The inclusion of the correct amount of noise induces regular oscillations, a phenomenon known as autonomous SR or coherence resonance. It can be either understood in terms of a noisy precursor of a bifurcation, for instance, a Hopf bifurcation or a homoclinic bifurcation or as a stochastic limit cycle (Pikovsky and Kurths 1997). If in addition to the stochastically induced oscillation an external millennial-scale signal is coupled to the coupled climate model, the possibility is created that the stochastic limit cycle couples nonlinearly to the external forcing. The resulting dynamics can be described in terms of the concept of nonautonomous SR.

Systems exhibiting coherent resonant behavior such as ours have not been discussed extensively in the climate literature. To our knowledge the only paper dealing with excitable climate dynamics theoretically is the one by Cessi (1996), who analyzes a conceptual model for oceanic convection (Welander 1986). This simple model exhibits remarkable dynamics: The convection model oscillates when the freshwater fluxes exceed a critical threshold value. However, stochastically kicked, the 
model is able to generate flip-flop oscillations in a parameter range in which the deterministic system has a stable stationary state. Furthermore, it was observed in that study that the length of the flip-flop oscillations depends critically on the mean value of the freshwater flux and also the noise level. Close to the bifurcation point the period attains arbitrarily long periods. As will be discussed in a forthcoming study (Abshagen and Timmermann 2002, manuscript submitted to J. Phys. Oceanogr., hereafter AAT) this behavior can be understood in terms of a codimension 2 bifurcation (TakensBogdanov point) resulting in a homoclinic bifurcation and coherence resonance.

Our coupled climate model revealed very similar behavior to the conceptual convection model discussed by Cessi (1996) and revisited by AAT:

- Relaxation oscillations can be kicked off stochastically, even if the deterministic system is in a stationary state.

- In addition to stochastic forcing, mean freshwater forcing is another crucial process, which governs the period of this relaxation oscillation.

- Once excited, the relaxation oscillation attains its full amplitude immediately.

- The period of the oscillation is sensitive to the amplitude of the stochastic forcing.

The idea that DO oscillations are related to CR has been discussed briefly by Ganopolski and Rahmstorf (2002). Their results are qualitatively confirmed by our experiments. Our study provides also a theoretical explanation of these results.

\section{Summary}

We have found that a specific type of resonance (coherence resonance $=$ autonomous stochastic resonance) can be regarded as a prototype for millennial-scale climate variations and possibly also for Dansgaard-Oeschger events. Our low-order coupled climate model revealed that massive meltwater pulses, mimicking Heinrich events, create conditions favorable for the excitation of millennial-scale variability. This leads to a dynamical concept for Bond cycles and might explain also the absence of Dansgaard-Oeschger events during the Holocene. ${ }^{7}$ Moreover, our model results suggest that sea ice plays an important role in amplifying the atmospheric response to THC anomalies. The timescale of the stochastically excited millennial-scale oscillations depends strongly on both the noise level and the mean freshwater forcing of the ocean. In particular, for large

\footnotetext{
${ }^{7}$ The "1500-yr" mode observed during the Holocene (Bond et al. 1997) appears to be related to changes of the solar constant (Bond et al. 2001). In addition, there are new evidences (Bond et al. 2001, electronical supplement) that the timescale of the millennial-scale Holocene mode amounts to about $900 \mathrm{yr}$, rather than $1500 \mathrm{yr}$. We think that no characteristics with the DO mode are shared.
}

freshwater anomalies we observe that the DO limit cycle operates close to a saddle node. For a certain parameter choice we observe a merging of the limit cycle and the saddle node, giving rise to a homoclinic orbit. Hence, a homoclinic bifurcation in parameter space shapes the dynamics of the millennial-scale climate oscillations and rectifies their period nonlinearly. What cannot be explained here is the weak millennial-scale Holocene mode observed by Bond et al. (1997) that has only very small impact on atmospheric temperatures as compared to the DO cycles.

Some aspects of our paper have been discussed already in previous studies:

- The existence of a Hopf bifurcation for the THC being at the core of the generation of century to millennialscale variability (Marotzke 1990; Weaver and Sarachik 1991; Winton 1993; Tziperman et al. 1994; Sakai and Peltier 1997, 1999; Bjornsson and Mysak 2001).

- The role of noise in exciting DO-like variability during the last glacial period (Ganopolski and Rahmstorf 2002).

- The interference of Heinrich events and DO cycles (Sakai and Peltier 1999; Paillard 1995).

- The importance of vertical and horizontal diffusivity in determining the length of DO cycles (Sakai and Peltier 2001).

- The Bond cycle might originate from the interaction between DO cycles, and an ice sheet relaxation oscillation, associated with the dynamics of Heinrich events (Schulz et al. 2002).

The new aspects of our paper are summarized as follows:

- Heinrich events can excite DO cycles, as anticipated by Paul and Schulz (2002).

- The timescale of DO cycles can be decomposed into a linear and a nonlinear deterministic part as well as into a stochastic contribution, governing the length of the stadial phases.

- The merger of the DO limit cycle and a saddle node, creating a homoclinic bifurcation is an important nonlinear element in generating long-term THC variability (see Fig. 5).

- Noise-induced transitions and oscillations within the THC are an important feature for a nonlinear rectification of the climate mean state.

- Coherent resonant DO cycles couple easily to an external periodic forcing. This concept of SR is far more complex than the classical SR concept of Nicolis (1982), which assumes stable equilibria.

Some of these results can be summarized within the schematic bifurcation diagram of Fig. 10. A weak freshwater forcing is associated with a steady interglacial THC. Increasing the freshwater flux leads to a Hopf bifurcation (square) and millennial-scale oscillations emerge between a stadial and an interstadial state. Increasing the freshwater forcing further results in a sta- 


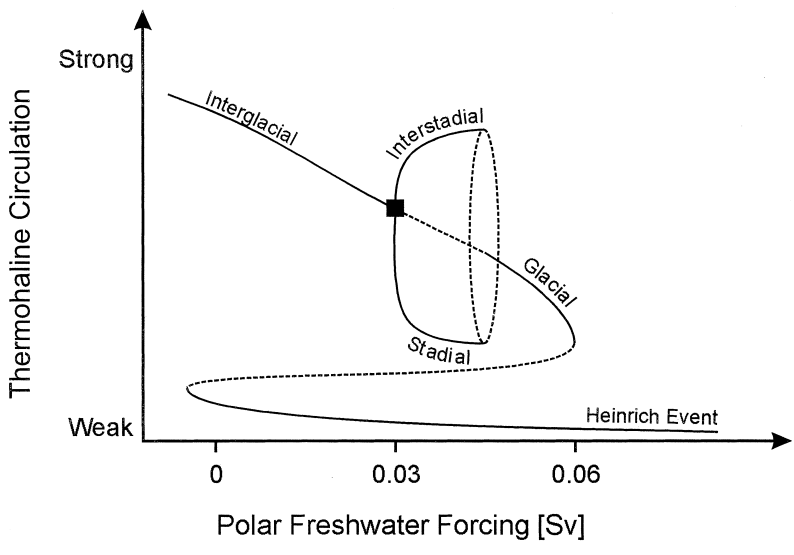

FIG. 10. Schematic bifurcation diagram of the stochastically forced THC as a function of the freshwater forcing in polar latitudes. The dotted lines represent unstable solutions (saddle nodes). The square indicates the presence of a Hopf bifurcation.

tionary glacial THC state, which is quasi-steady in the sense that the oscillation attains very long periods. Subsequently this state loses stability through a saddle-node bifurcation and a Heinrich mode (collapsed THC) is the result. The proximity between the unstable THC state, originating from the saddle-node bifurcation and the DO stochastic limit cycle indicates the existence of homoclinic dynamics, and hence, the possibility for the generation of very long nonlinear timescales.

Acknowledgments. This work is supported by the Deutsche Forschungs Gemeinschaft (DFG). HG is supported by the NOAA Postdoctoral Program in Climate and Global Change, administered by the University Corporation for Atmospheric Research.

\section{REFERENCES}

Aeberhardt, M., M. Blatter, and T. F. Stocker, 2000: Variability on the century time scale and regime changes in a stochastically forced zonally averaged ocean-atmosphere model. Geophys. Res. Lett., 27, 1303-1306.

Alley, R. B., 1998: Icing the North Atlantic. Nature, 392, 335.

_ , and D. R. MacAyeal, 1994: Ice rafted debris associated with binge/purge oscillations of the Laurentide ice sheet. Paleoceanography, 9, 503-511.

- S. Anandakrishnan, and P. Jung, 2001: Stochastic resonance in the North Atlantic. Paleoceanography, 16, 190-198.

Benzi, R., A. Sutera, and A. Vulpiani, 1981: The mechanism of stochastic resonance. J. Phys. A, 14, L453-L457.

-, G. Parisi, A. Sutera, and A. Vulpiani, 1982: Stochastic resonance in climatic change. Tellus, 34, 10-16.

Berglund, N., and H. Kunz, 1999: Memory effects and scaling laws in slowly driven systems. J. Phys., 32A, 15-39.

- and B. Gentz, 2002: The effect of additive noise on dynamical hysteresis. Nonlinearity, 15, 605-632.

Bjornsson, H., and L. A. Mysak, 2001: Present-day and last-glacicalmaximum ocean thermohaline circulation in a zonally averaged coupled ocean-sea-ice-atmosphere model. J. Climate, 14, 1422 1439.

Bond, G. C., and R. Lotti, 1995: Iceberg discharges into the North Atlantic on millennial timescales during the last glaciation. Science, 267, 1005-1010.
_ _ and Coauthors, 1992: Evidence for massive discharges of icebergs into the North Atlantic Ocean during the last glacial period. Nature, 360, 245-249.

- W. S. Broecker, S. Johnsen, J. McManus, L. Labeyrie, J. Jouzel, and G. Bonani, 1993: Correlations between climate records from North Atlantic sediments and Greenland ice. Nature, 365, 143 147.

__ and Coauthors, 1997: A pervasive millennial-scale cycle in North Atlantic Holocene and glacial climates. Science, 278, $1257-1266$.

— lantic climate during the Holocene. Science, 294, 2130-2136.

Cessi, P., 1996: Convective adjustment and thermohaline excitability. J. Phys. Oceanogr., 26, 481-491.

Chen, D., R. Gerdes, and G. Lohmann, 1995: A 1-D atmospheric energy balance model developed for ocean modeling. Theor. Appl. Climatol., 51, 25-38.

Clarke, G. K. C., 1987: Fast glacier flow: Ice streams, surging, and tidewater glaciers. J. Geophys. Res., 92, 8835-8841.

Dansgaard, W., S. J. Johnson, H. B. Clausen, D. Dahl-Jensen, N. Hammer, and C. U. Oeschger, 1984: North Atlantic climatic oscillations revealed by deep greenland ice cores. Climate Processes and Climate Sensitivity, Geophys. Monogr., No. 29, Amer. Geophys. Union, 288-298.

Gammaitoni, L., P. Hänggi, P. Jung, and F. Marchesoni, 1998: Stochastic resonance. Rev. Mod. Phys., 70, 223-288.

Gang, H., T. Ditzinger, C. Z. Ning, and H. Haken, 1993: Stochastic resonance without external periodic force. Phys. Rev. Lett., 71, 807-813.

Ganopolski, A., and S. Rahmstorf, 2001: Rapid changes of glacial climate simulated in a coupled climate model. Nature, 409, 153158.

— chastic resonance. Phys. Rev. Lett., 88, 038501-1-038501-4.

Gildor, H., and E. Tziperman, 2001: A sea ice climate switch mechanism for the 100-kyr glacial cycles. J. Geophys. Res., 106 (C5), 9117-9133.

Haarsma, R. J., J. D. Opsteegh, F. M. Selten, and X. Wang, 2001: Rapid transitions and ultra-low-frequency behaviour in a $40 \mathrm{kyr}$ integration with a coupled climate model of intermediate complexity. Climate Dyn., 17, 559-570.

Haltiner, G. J., and R. T. Williams, 1980: Numerical prediction and dynamic meteorology. John Wiley and Sons, $477 \mathrm{pp}$.

Hammer, C., P. A. Mayewski, D. Peel, and M. Stuiver, 1997: Preface. J. Geophys. Res., 102, 26 315-26 316.

Haney, R. L., 1971: Surface thermal boundary condition for ocean circulation models. J. Phys. Oceanogr., 1, 241-248.

Heinrich, H., 1988: Origin and consequences of cyclic ice rafting in the northeast Atlantic Ocean during the past 130000 years. Quat. Res., 29, 143-152.

Hulbe, C. L., 1997: An ice shelf mechanism for Heinrich layer production. Paleoceanography, 12, 711-717.

Keeling, C. D., and T. P. Whorf, 2000: The 1800-year oceanic tidal cycle: A possible cause of rapid climate change. Proc. Natl. Acad. Sci. USA, 97, 3814-3819.

Kloeden, P. E., and E. Platen, 1992: Numerical Solution of Stochastic Differential Equations. Springer, 632 pp.

Lambeck, K., and J. Chappell, 2001: Sea level change through the last glacial cycle. Science, 292, 679-686.

Lang, C., W. Leuenberger, J. Schwander, and S. Johnsen, 1999: Rapid temperature variations in central Greenland 70,000 years ago. Science, 286, 934-937.

Latif, M., E. Roeckner, U. Mikolajewicz, and R. Voss, 2000: Tropical stabilization of the thermohaline circulation in a greenhouse warming simulation. J. Climate, 13, 1809-1813.

Lindner, B., and L. Schimansky-Geier, 1999: Analytical approach to the stochastic FitzHugh-Nagumo system and coherence resonance. Phys. Rev., 60E, 1063-1065.

, and - 2000: Coherent and stochastic resonance in a twostate system. Phys. Rev., 61E, 6103-6110. 
Longtin, A., 1997: Autonomous stochastic resonance in bursting neurons. Phys. Rev. 55E, 868-876.

MacAyeal, D. R., 1993a: A low-order model of growth/purge oscillations of the Laurentide ice sheet. Paleoceanography, 8, 767773.

_- 1993b: Binge/purge oscillations of the Laurentide ice sheet as a cause of North Atlantic's Heinrich events. Paleoceanography, 8, 775-784.

Manabe, S., and R. F. Strickler, 1964: Thermal equilibrium of the atmosphere with a convective adjustment. J. Atmos. Sci., 21, 342.

_ and R. J. Stouffer, 1995: Simulation of abrupt climate change induced by freshwater input to the North Atlantic Ocean. Nature, 378, 165-167.

Marotzke, J., 1990: Instabilities and multiple equilibria of the thermohaline circulation. Ph.D. thesis, Berichte aus dem Institut für Meereskunde, Kiel, Germany, 126 pp.

_ , and P. H. Stone, 1995: Atmospheric transports, the thermohaline circulation, and flux adjustments in a simple coupled model. $J$. Phys. Oceanogr., 25, 1350-1364.

Marshall, S. J., and G. K. C. Clarke, 1997: A continuum mixture model of ice stream thermomechanics in the Laurentide ice sheet. 2. Application to the Hudson Strait ice stream. J. Geophys. Res., 102 (B9), $20615-20637$.

- and - , 1999: Modeling North American freshwater runoff through the last glacial cycle. Quat. Res., 52, 300-315.

Mikolajewicz, U., and E. Maier-Reimer, 1994: Mixed boundary conditions in ocean general circulation models and their influence on the stability of the model's conveyor belt. J. Geophys. Res., 99 (C11), 22 633-22 644.

Monahan, A. H., A. Timmermann, and G. Lohmann, 2002: Comments on "Noise-induced transitions in a simplified model of the thermohaline circulation." J. Phys. Oceanogr., 32, 1112-1116.

Neiman, A., P. Saparin, and L. Stone, 1997: Coherence resonance at noisy precursors of bifurcation in nonlinear dynamical systems. Phys. Rev., 56E, 270-273.

Nicolis, C., 1982: Stochastic aspects of climatic transitions-Response to a periodic forcing. Tellus, 34, 1-9

Paillard, D., 1995: The hierarchical structure of glacial climatic oscillations: Interactions between ice-sheet dynamics and climate. Climate Dyn., 11, 162-177.

Paul, A., and M. Schulz, 2002: Holocene climate variability on centennial-to-millennial time scales: 2. Internal feedbacks and external forcings as possible causes. Climate Development and History of the North Atlantic Realm, G. Wefer, et al., Eds., Springer-Verlag, 55-73.

Peltier, W. R., and K. Sakai, 2001: Dansgaard Oeschger oscillations: A hydrodynamic theory. The Northern North Atlantic: A Changing Environment, P. Schaefer et al., Eds., Springer-Verlag, 423440.

Pierce, D., T. P. Barnett, and U. Mikolajewicz, 1995: Competing roles of heat and freshwater flux in forcing thermohaline oscillations. J. Phys. Oceanogr., 25, 2046-2064.

— , K.-Y. Kim, and T. P. Barnett, 1996: Variability of the thermohaline circulation in an ocean general circulation model coupled to an atmospheric energy balance model. J. Phys. Oceanogr., 26, 725-738.

Pikovsky, A., and J. Kurths, 1997: Coherence resonance in a noisedriven excitable system. Phys. Rev. Lett., 78, 775-778.

Pradines, J. R., G. V. Osipov, and J. J. Collins, 1999: Coherence resonance in excitable and oscillatory systems: The essential role of slow and fast dynamics. Phys. Rev., 60E, 6407-6410.

Rahmstorf, S., 1997: Risk of sea-change in the Atlantic. Nature, $\mathbf{3 8 8}$ $825-826$.

_- and A. Ganopolski, 1999: Long-term global warming scenarios computed with an efficient coupled climate model. Climatic Change, 43, 353-367.

Rivin, I., and E. Tziperman, 1997: Linear versus self-sustained interdecadal thermohaline variability in a coupled box model. $J$. Phys. Oceanogr., 27, 1216-1232.
Rosenblum, M., A. Pikovsky, and J. Kurths, 1996: Phase synchronization of chaotic oscillators. Phys. Rev. Lett., 76, 1804-1807.

Sakai, K., and W. R. Peltier, 1995: A simple model of the Atlantic thermohaline circulation: Internal and forced variability with paleoclimatological implications. J. Geophys. Res., 100 (C7), 13 455-13 479.

— thermohaline circulation: Paleocenaographic analyses of the origins of ice-age variability. J. Geophys. Res., 101 (C10), $22535-$ 22562.

— atmosphere-ocean climate model. J. Climate, 10, 949-967.

_, and _ 1999: A dynamical system model of the DansgaardOeschger oscillation and the origin of the Bond cycle. J. Climate, 12, 2238-2255.

- , and - 2001: The influence of deep ocean diffusivity on the temporal variability of the thermohaline circulation. The Oceans and Rapid Climate Change: Past, Present and Future, D. Seidov and M. Maslin, Eds., Amer. Geophys. Union, 227-242.

Sarnthein, M., and Coauthors, 2001: Fundamental modes and abrupt changes in North Atlantic circulation and climate over the last $60 \mathrm{ky}$-Concepts, reconstructions and numerical modeling. The Northern North Atlantic: A Changing Environment, P. Schfer et al., Eds., Springer-Verlag, 365-410.

Schmittner, A., and T. F. Stocker, 1999: The stability of the thermohaline circulation in global warming experiments. J. Climate, 12, 1117-1133.

Schulz, M., 2002: On the 1470-year pacing of Dansgaard-Oeschger warm events. Paleoceanography, 17, 1014, doi:10.1029/2000PA000571.

—_, A. Paul, and A. Timmermann, 2002: Relaxation oscillators in concert: A framework for climate change at millennial timescales during the late Pleistocene. Geophys. Res. Lett., 29, 2193, doi: 10.1029/2002GL016144.

Severinghaus, J. P., and E. J. Brook, 1999: Abrupt climate change at the end of the last glacial period inferred from trapped air in polar ice. Science, 286, 930-934.

Stocker, T. F., R. Knutti, and G.-K. Plattner, 2001: The future of the thermohaline circulation-A perspective. The Oceans and Rapid Climate Change: Past, Present, and Future, Geophys. Monogr., No. 126, Amer. Geophys. Union, 277-293. 2001.

Stommel, H. M., 1961: Thermohaline convection with two stable regimes of flow. Tellus, 13, 224-230.

Stone, E., and P. Holmes, 1989: Random perturbations of heteroclinic attractors. SIAM J. Appl. Math., 50, 726-743.

_ heteroclinic cycles. Chaos, 9, 499-506.

Stuiver, M., and P. M. Grootes, 2000: GISP2 oxygen isotope ratios. Quat. Res., 53, 277-284.

Timmermann, A., and G. Lohmann, 2000: Noise-induced transitions in a simplified model of the thermohaline circulation. J. Phys. Oceanogr., 30, 1891-1900.

_ M. Latif, and R. Voss, 1998: Northern Hemispheric interdecadal variability: A coupled air-sea mode. J. Climate, 11, 1906-1931.

Tziperman, E., 1997: Inherently unstable climate behaviour due to weak thermohaline ocean circulation. Nature, 386, 592-595.

— , and H. Gildor, 2002: The stabilization of the thermohaline circulation by the temperature-precipitation feedback. J. Phys. Oceanogr., 32, 2707-2714.

_ _ J. R. Toggweiler, Y. Feliks, and K. Bryan, 1994: Instability of the thermohaline circulation with respect to mixed boundary conditions: Is it really a problem for realistic models? J. Phys. Oceanogr., 24, 217-232.

UNESCO, 1981: 10th report of the joint panel on oceanographic tables and standards. UNESCO Tech. Papers in Marine Science 36, Paris, France, 55 pp.

van den Geel, B., O. M. Raspopov, H. Renssen, J. van der Plicht, V. A. Dergachev, and H. A. J. Meijer, 1999: The role of solar forcing upon climate change. Quat. Sci. Rev., 18, 331-338.

Weaver, A. J., and E. S. Sarachik, 1991: The role of mixed boundary 
conditions in numerical models of the ocean's climate. J. Phys. Oceanogr., 21, 1470-1493.

—, and T. M. C. Hughes, 1994: Rapid interglacial climate fluctuations driven by North Atlantic ocean circulation. Nature, 367, 447-450.

Welander, P., 1986: A simple heat-salt oscillator. Dyn. Atmos. Oceans, 6, 233-242.

Winton, M., 1993: Deep decoupling oscillations of the oceanic thermohaline circulation. Ice in the Climate System, W. R. Peltier, Ed., NATO ASI Series, Vol. 12, Springer-Verlag, 417-432.

, 1997: The effect of cold climate upon North Atlantic deep water formation in a simple ocean-atmosphere model. $\mathrm{J}$. Climate, 10, 37-51.

_, and E. S. Sarachik, 1993: Thermohaline oscillations induced by strong steady salinity forcing of ocean general circulation models. J. Phys. Oceanogr., 23, 1389-1410.

Wright, D. G., and T. F. Stocker, 1991: A zonally averaged model of the thermohaline circulation. Part I: Model development and flow dynamics. J. Phys. Oceanogr., 21, 1713-1724.

Zhang, J., R. W. Schmitt, and R. X. Huang, 1999: The relative influence of diapycnal mixing and hydrologic forcing on the stability of the thermohaline circulation. J. Phys. Oceanogr., 29, 1096-1108. 